\title{
Cyclin-Dependent Kinase 5/p35 Contributes Synergistically with Reelin/Dab1 to the Positioning of Facial Branchiomotor and Inferior Olive Neurons in the Developing Mouse Hindbrain
}

\author{
Toshio Ohshima,, ${ }^{1}$ Masaharu Ogawa, ${ }^{2}$ Kyoko Takeuchi, ${ }^{2}$ Satoru Takahashi, ${ }^{3}$ Ashok B. Kulkarni, ${ }^{3}$ and \\ Katsuhiko Mikoshiba ${ }^{1}$ \\ 1 Laboratory for Developmental Neurobiology and ${ }^{2}$ Cell Culture Development, Brain Science Institute, The Institute of \\ Physical and Chemical Research (RIKEN), Wako, Saitama 351-0198, Japan, and ${ }^{3}$ Functional Genomics Unit, National \\ Institute of Dental and Craniofacial Research, National Institutes of Health, Bethesda, Maryland 20892
}

Cyclin-dependent kinase 5 (Cdk5)/p35 is a serine/threonine kinase, and its activity is detected primarily in postmitotic neurons. Mice lacking Cdk5/p35 display migration defects of the cortical neurons in the cerebrum and cerebellum. In this study, we demonstrate that although most brainstem nuclei are found in their proper positions, the motor nucleus of the facial nerve is ectopically located and neurons of the inferior olive fail to position correctly, resulting in the lack of their characteristic structures in the hindbrain of Cdk5-/- mice. Despite the defective migration of these neurons, axonal exits of the facial nerve from brainstem and projections of the inferior cerebellar axons appear unchanged in Cdk5-/- mice. Defective neuronal migration in Cdk5-/- hindbrain was rescued by the neuronspecific expression of Cdk5 transgene. Because developmental defects of these structures have been reported in reeler and Dab1 mutant mice, we analyzed the double-null mutants of p35 and Dab1 and found more extensive ectopia of VII motor nuclei in these mice. These results indicate that Cdk5/p35 and Reelin signaling regulates the selective mode of neuronal migration in the developing mouse hindbrain.

Key words: Cdk5; p35; reelin; disabled-1; facial branchiomotor neuron; inferior olive
Cyclin-dependent kinase 5 (Cdk5) is a member of the family of Cdks. Unlike other Cdks, Cdk5 activity is detected mainly in postmitotic neurons (Tsai et al., 1993). Association of Cdk5 with a neuron-specific regulatory subunit, either p35 or its isoform p39, is critical for its kinase activity (Lew et al., 1994; Tsai et al., 1994; Tang et al., 1995). Cdk5-/- mice exhibit perinatal death associated with disruption of the cortical laminar structures, apparently because of defective neuronal migration (Ohshima et al., 1996; Gilmore et al., 1998), whereas p35-/- mice display milder phenotypes than Cdk5-/- mice because of the redundancy of Cdk5 regulatory subunits (Chae et al., 1997; Kwon and Tsai, 1998; Ohshima et al., 2001). Moreover, p35-/-p39-/- mice display a phenotype identical to that of $\mathrm{Cdk} 5-/-$ mice, confirming redundancy in these subunits (Ko et al., 2001). Neuronal birth-date labeling by bromodeoxyuridine revealed an inverted layer structure in the cerebral cortex of $\mathrm{Cdk} 5-/-$ mice (Gilmore et al., 1998). An inverted pattern of layer structure in the cerebral cortex is also a well known characteristic of reeler and scrambler/yotari mice. These mutant mice exhibit nearly identical phenotypes, suggesting that the gene products mutated in these mice, Reelin

\footnotetext{
Received Oct. 4, 2001; revised Feb. 5, 2002; accepted Feb. 20, 2002.

This work was partially supported by grants-in-aid from the Ministry of Education, Science, and Culture of Japan to T.O. and by National Institute of Dental and Craniofacial Research, National Institutes of Health Grant Z01DE00694-010DIR to A.B.K. We thank Drs. B. W. Howell and J. A. Cooper for the gift of Dab1 antibody and Dab1 cDNA. The $2 \mathrm{H} 3$ and islet-1 antibodies were obtained from the Developmental Studies Hybridoma Bank (University of Iowa, Iowa City, IA). We thank Drs. T. Saito, M.-M. Portier, C. Redies, J.-F. Brunet, T. M. Jessell, and D. S. Latchman for in situ probes. We also thank Drs. Y. Sugitani and T. Terashima for technical advice and Dr. May Jo Danton for critical reading of this manuscript.

Correspondence should be addressed to Toshio Ohshima, Laboratory for Developmental Neurobiology, Brain Science Institute, RIKEN, 2-1 Hirosawa, Wako, Saitama 351-0198, Japan. E-mail: ohshima@brain.riken.go.jp.

Copyright (C) 2002 Society for Neuroscience $0270-6474 / 02 / 224036-09 \$ 15.00 / 0$
}

and Dab1, respectively, act in a common signaling pathway during cortical development (D’Arcangelo et al., 1995; Ogawa et al., 1995; Sheldon et al., 1997; Yoneshima et al., 1997; Rice et al., 1998; Howell et al., 1999). In wild-type mice, successive waves of migrating neurons split the preplate into the marginal zone and subplate and form the cortical plate in an inside-out manner. In reeler and scrambler/yotari mutants, the migrating cortical neurons appear incapable of splitting the preplate, and the cortical-plate neurons stack up in inverted order beneath the preplate. In Cdk5-/- and p35-/- mice, the earlier-born neurons successfully split the preplate; however, the late-born neurons stack up in an inverted layer under the subplate. Two general modes of neuronal migration have been described in the developing nervous system: nuclear translocation (also called nucleokinesis) and "locomotion" (Book and Morest, 1990), and both the modes have been observed in the slice cultures of the cerebral cortex (Miyata et al., 2001; Nadarajah et al., 2001). We have proposed that earlier-born neurons might use a Cdk5-independent nucleartranslocation mode, whereas the migration mode of late-born neurons is Cdk5-dependent in the cerebral cortex (Gilmore et al., 1998).

Recently, developmental defects of brainstem structures, including the lack of the inferior olive (IO), have been reported in Cdk5-/- and p35-/-p39-/- mice (Ko et al., 2001). However, detailed characterization of neuronal migration defects in these abnormalities remains to be elucidated. To characterize Cdk5dependent and -independent modes of neuronal migrations, we have analyzed neuronal migrations in detail in the hindbrain of Cdk5-/- mice. Selective defects in neuronal migration were identified in the facial nucleus and IO; however, the rest of brainstem nuclei, including the pontine nucleus, formed normally. Because neuronal migration defects in the facial nucleus and IO 

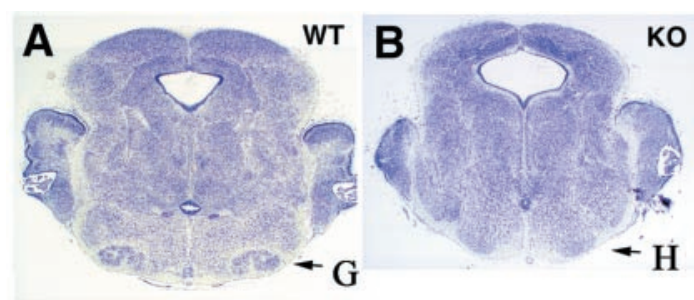

KO
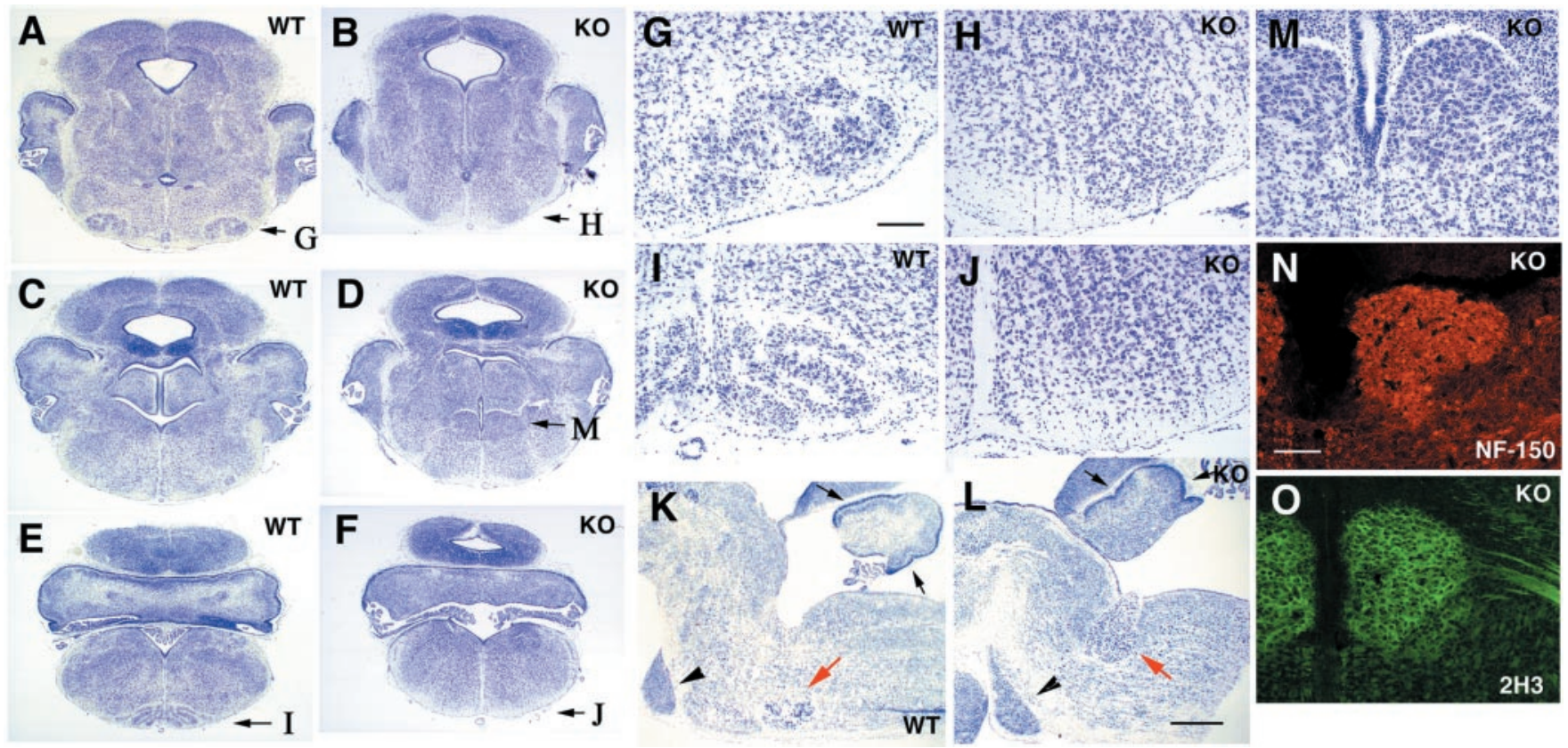

Figure 1. Selective loss of the VIIth motor nucleus and IO in Cdk5 $-/-$ mice. Nissl-stained coronal $(A-J, M)$ and sagittal $(K, L)$ sections from Cdk5 $+/+$ $(A, C, E, G, I, K)$ and $\mathrm{Cdk} 5-/-(B, D, F, H, J, M)$ mice at E18.5. Genotypes are indicated as wild type $(W T)(\mathrm{Cdk5+/+)}$ and knock-out $(K O)$ $(\mathrm{Cdk} 5-/-) . A-J$ and $M$ are paraffin sections stained with cresyl violet. $K$ and $L$ are frozen sections stained with toluidine blue. $G-J$ and $M$ are higher magnifications of a specific part of the sections in $A, B, E, F$, and $D$, respectively; the magnified area in each section is indicated by a letter on the bottom right corner in $A, B$, and $D-F$. A loss of typical structures of the facial nerve nucleus $(B, H)$ and $\mathrm{IO}(F, J)$ is observed in the null mice. As seen in the sagittal sections, the appearance and position of the pontine nucleus (arrowheads) are similar in Cdk5+/+ and Cdk5-/ mice $(K, L)$. In Cdk5-/hindbrain, an abnormal cell mass is seen in $L$ and $M$. This ectopic mass ( $M$ and red arrow in $L$ ) consists of postmitotic neurons positively stained with the anti-neurofilament antibodies NF-150 $(N)$ and 2H3 $(O)$. Black arrows in $K$ and $L$ indicate the external granule cell layer of the cerebellum. The red arrow in $K$ indicates the location of VIIth nucleus in $\mathrm{Cdk} 5+/+$ mice. Arrowheads in $K$ and $L$ indicate pontine nucleus. $A-F, G-J$, and $M-O$ are at the same magnifications, respectively. Scale bars: $G, N, 120 \mu \mathrm{m} ; L, 700 \mu \mathrm{m}$.

have been reported previously in reeler mice, we have analyzed any correlation of Cdk5/p35 with Reelin signaling and its effect on neuronal migration using double-mutant mice for p35 and Dab1.

\section{MATERIALS AND METHODS}

Animals. Cdk5 and p35 mutant mice were generated as described previously (Ohshima et al., 1996, 2001) and maintained in C57BL/6J and in $129 / \mathrm{Sv} \times \mathrm{C} 57 \mathrm{BL} / 6 \mathrm{~J}$ backgrounds, respectively. Yotari mutants were maintained in C57BL/6 × 129/SvJ hybrid background (Yoneshima et al., 1997). Double-mutant mice were obtained after crossing each mouse line, and genotypes for $\mathrm{Cdk} 5, \mathrm{p} 35$, and Dab1 alleles were determined by PCR as described previously (Ohshima et al., 2001). p35-Cdk5 × Cdk5 null (Cdk5TgKO) mice were generated as described previously (Tanaka et al., 2001). All mice were housed in the standard mouse facility and were fed an autoclaved diet and water.

Immunohistochemical study and in situ hybridization. Anesthetized mice were perfused transcardially with $4 \%$ paraformaldehyde in $0.1 \mathrm{M}$ phosphate buffer, $\mathrm{pH}$ 7.4. Ten micrometer cryostat sections were stained with $0.9 \%$ toluidine blue solution for Nissl stain. For immunohistochemistry, antibodies were diluted in PBS $/ 0.01 \%$ Triton X-100 and $5 \%$ bovine serum albumin. Primary antibodies were polyclonal anti-p75 NGF receptor (Chemicon, Temecula, CA; diluted 1:200), polyclonal antineurofilament $150 \mathrm{kDa}$ (Chemicon; 1:400), polyclonal anti-choline acetyltransferase (ChAT) (Chemicon; 1:2000), 2H3 (obtained from the Developmental Studies Hybridoma Bank, University of Iowa, Iowa City, IA; monoclonal supernatant; 1:200), polyclonal anti-peripherin (Chemicon; 1:400), and anti-Dab1 (gift from Dr. J. Cooper, Seattle, WA; 1:400). For fluorescent staining, fluorescein isothiocyanate-conjugated antimouse $\operatorname{IgG}$ and $\mathrm{Cy} 3$-conjugated anti-rabbit $\operatorname{IgG}$ (Chemicon) were used at a 1:400 dilution. For paraffin sections, the heads were removed from embryos and immediately fixed by immersion in a fixative consisting of 95\% ethanol and 5\% acetic acid. Tissue blocks were embedded in paraffin after dehydration using absolute ethanol and xylene and sequentially sectioned at $10 \mu \mathrm{m}$ thickness on a rotary microtome. After mounting on glass slides, the sections were air-dried on a hot plate at $44^{\circ} \mathrm{C}$ and then stained with $0.5 \%$ cresyl violet for Nissl staining. Whole-mount immunohistochemistry with $2 \mathrm{H} 3$ antibody was performed as described previously (Taniguchi et al., 1997). In situ hybridizations were performed using digoxigenin-labeled probe as described previously (Ohshima et al., 2001), and the following probes were used: reelin (D'Arcangelo et al., 1995), Dab1 (Howell et al., 1997), peripherin (Escurat et al., 1990), cadherin-8 (Korematsu and Redies, 1997), Phox2b (Pattyn et al., 2000), ER81 (Arber et al., 2000), and Brn3b (Wyatt et al., 1998).

1,1'-dioctadecyl-3,3,3',3'-tetramethylindocarbocyanine perchlorate tracing: retrograde labeling of $I O$. After intracardiac perfusion with $4 \%$ paraformaldehyde in $0.1 \mathrm{M}$ phosphate buffer, $\mathrm{pH} 7.4$, a small occipital craniotomy was performed to expose the cerebellum of embryonic day 18.5 (E18.5) Cdk5+/+ and Cdk5-/- embryos. Several small crystals of $1,1^{\prime}$-dioctadecyl-3,3,3',3'-tetramethylindocarbocyanine perchlorate (DiI) were inserted medially and laterally into the cerebellar tissue of the right hemicerebellum to label most of the IO neurons. The brains along with their skulls were kept in the same fixative for $4-6$ weeks in the dark at $37^{\circ} \mathrm{C}$. The brains were then dissected from their skulls, embedded in $2 \%$ agarose, and cut into sections at a thickness of $100 \mu \mathrm{m}$ with a vibratome. The sections were photographed with a rhodamine filter.

\section{RESULTS}

Selective migration defects in the facial branchiomotor and $\mathrm{IO}$ neurons of Cdk5-I- mice

We first compared the overall structure of the E18.5 hindbrains of $\mathrm{Cdk} 5+/+$ mice with that of the $\mathrm{Cdk} 5-/-$ mice using Nisslstained coronal and sagittal sections (Fig. $1 A-L$ ). This comparison revealed that several neuronal nuclei in $\mathrm{Cdk} 5-/-$ mice, the IVth, Vth, Xth and XIIth cranial motor nerve nuclei, were comparable with those in the $\mathrm{Cdk} 5+/+$ mice. Among the derivatives of the rhombic lip, pontine nuclei of $\mathrm{Cdk} 5-/-$ mice formed normally compared with the $\mathrm{Cdk} 5+/+$ mice (Fig. $1 K, L)$; how- 
Figure 2. Immunohistochemical characterization of a neuronal mass of facial branchiomotor neurons. Serial coronal sections from $\mathrm{Cdk} 5+/+(A-C)$ and $\mathrm{Cdk} 5-/-$ $(D-F)$ mice at E18.5 were stained with antip75 $(A, D)$, anti-NF150 $(B, E)$, and antiChAT $(C, F)$ antibodies. Both the facial nucleus in $\mathrm{Cdk} 5+/+$ mice and the neuronal mass in $\mathrm{Cdk} 5-/-$ mice are positive for these antibodies. $G-I$, Coronal sections from $\mathrm{Cdk} 5+/+(G, H)$ and $\mathrm{Cdk} 5-/-(I)$ mice at E14.5 stained with anti-peripherin antibody. The facial nerves $(f n)$, axonal bundles of FBM neurons, are formed early after the neurons are generated and extend dorsally toward the exit point at the $\mathrm{r} 4$ level. The facial nerve bends in parallel to the migration of the cell bodies, forming the "genu" of the facial nerve. Thus, the facial nerve exits at the rostral level $(G)$ from the facial nucleus (VII in $H$ ) in $\mathrm{Cdk} 5+/+$ mice. In $\mathrm{Cdk} 5-/-$ mice, the facial nerve extends from the neuronal mass (VII) and exits at the same level $(I)$. These results indicate that the neuronal mass in $\mathrm{Cdk} 5-/-$ mice consists of migratory-arrested FBM neurons at the site at which they were born. Scale bars: $F, 160 \mu \mathrm{m} ; I, 400 \mu \mathrm{m}$. Vg, Vth ganglia; $V I I$, VIIth ganglia; VII+VIIIg, VIIth and VIIIth ganglia; $W T$, wild type; $K O$, knock-out.
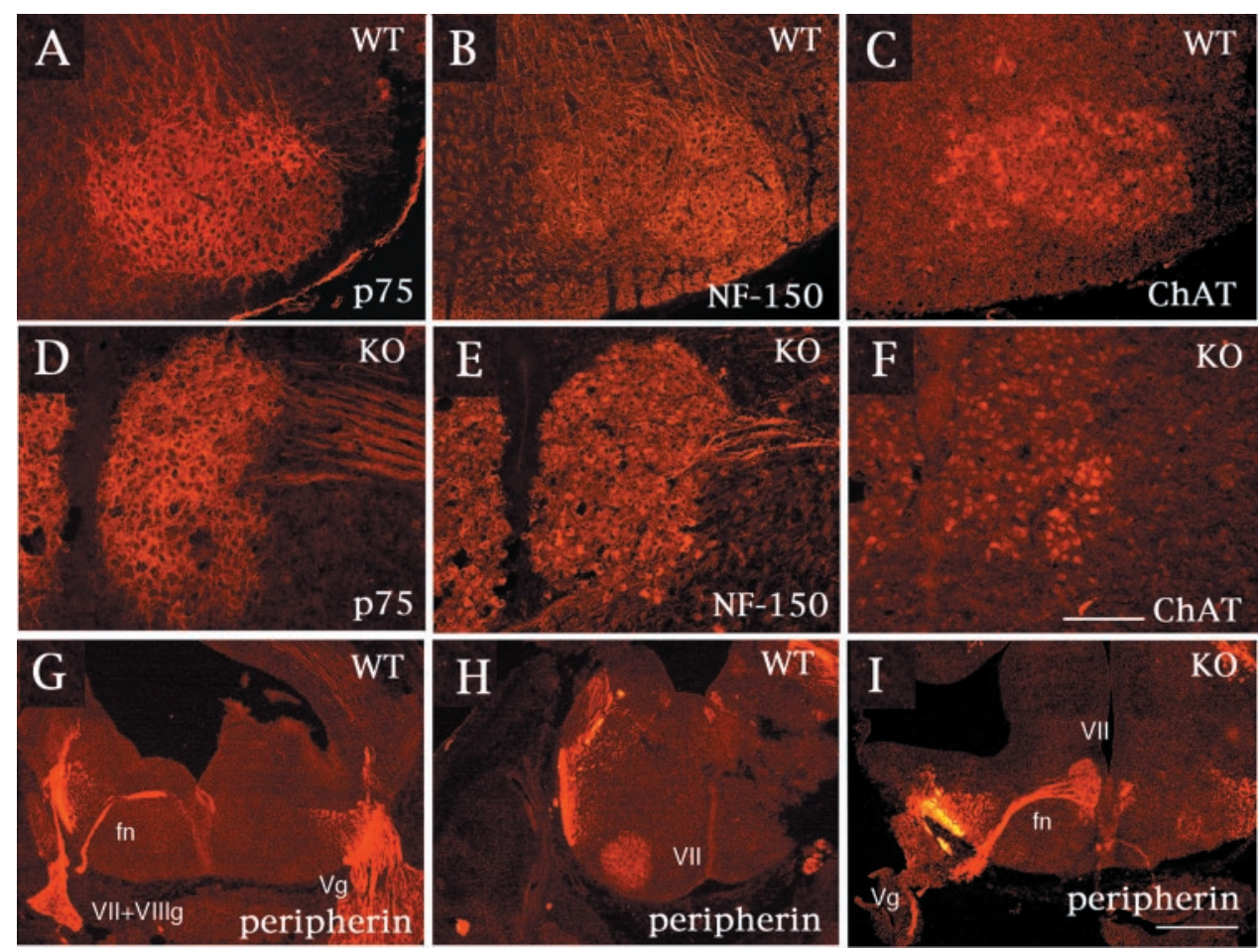

ever, the typical structure of IO was found to be absent in Cdk5-/- mice (Fig. $1 F, J)$. We also found a specific loss of facial branchiomotor (FBM) nucleus (Fig. $1 B, H)$ and an appearance of an ectopic mass consisting of relatively large cells in the dorsal pons in the Cdk5-/- hindbrain (Fig. $1 D, L, M)$. Immunostaining of this ectopic mass with neurofilament antibodies confirmed that it consisted of postmitotic neurons (Fig. 1N,O). This ectopic neuronal mass was located at the site at which FBM neurons arise; therefore, we assume that this structure is caused by the arrested migration of FBM neurons. To further confirm that the ectopic neurons are indeed FBM neurons, we used available antibodies and RNA probes to detect the markers that are expressed either in the FBM neurons or in cranial nuclei. Both FBM neurons in the wild-type mice and ectopic neurons in the Cdk5-/- mice stained positive for p75 nerve growth factor receptor and ChAT (Fig. $2 A-F$ ). For in situ hybridization, we used the following probes as markers for FBM neurons: peripherin (Escurat et al., 1990), Phox2b (Pattyn et al., 2000), and cadherin-8 (Korematsu and Redies, 1997). In situ hybridization studies with these probes revealed that ectopic neurons were positive for Phox $2 \mathrm{~b}$ and cadherin- 8 as well as peripherin as early as E14.5, when migration defects of FBM neurons became detectable in $\mathrm{Cdk} 5-/-$ mice (Fig. $3 A-L$ ). The normal appearance of the VIIth ganglia in $\mathrm{Cdk} 5-/-$ mice was confirmed by wholemount immunostaining with the $2 \mathrm{H} 3$ antibody at E11.5 (data not shown). At E12.5, using islet-1 immunostaining, we found that comparative numbers of FBM neurons were generated in Cdk5-/- mice (data not shown). These data strongly indicated that the ectopic neuronal mass consists of the migration-defective FBM neurons. Although neuronal cell bodies of FBM neurons in Cdk5-/- mice were ectopically located, their axons (facial nerve) extended normally and exited at the sites identical to those of the wild-type mice (Fig. $2 G-I$ ). Thus, despite their defective migration, the specification and axonal trajectory of FBM neurons are not disturbed by $\mathrm{Cdk} 5$ deficiency. To study the correla- tion between the defective migration of FBM neurons and Cdk5kinase deficiency, we subsequently analyzed the localization of FBM neurons in p35-/- and p35-/ $-\mathrm{Cdk} 5+/-$ mice at E18.5. We previously reported a $10 \%$ residual activity of C $\mathrm{dk} 5$ kinase in p35-/- hindbrain at postnatal day 5 (P5) (Ohshima et al., 2001). Additional reduction of this residual activity is expected in $\mathrm{p} 35-/$ $-\mathrm{Cdk} 5+/-$ mice. In p35-/- mice, the location of FBM neurons is comparable with that in $\mathrm{p} 35+/+$ mice. However, defective migration of FBM neurons, which appeared as elongated shapes of VIIth nuclei, was apparent in p35-/-Cdk5+/- mice at E18.5 (Fig. 3P,Q), as well as in the adult $\mathrm{p} 35-/-\mathrm{Cdk} 5+/-$ mice (data not shown). These results indicate that migration of FBM neurons is also dependent on Cdk5-kinase activity.

We subsequently attempted to identify the IO neurons in Cdk5-/- mice by two methods: (1) in situ hybridization with the IO-specific riboprobes ER81 (Chotteau-Lelievre et al., 1997; Arber et al., 2000) and Brn3b (Wyatt et al., 1998) and (2) a retrograde labeling of IO by DiI placement in the cerebellum. Neurons destined for IO are generated in the rhombic lip at E11 and migrate through the submarginal (intraparenchymal) stream. The IO appears at E14 as a cell crescent located at the ventral and medial aspects of the rhombencephalon (Fig. 4A), and then a progressive modeling leads to its typical foliated shape at E16 in the wild type (Fig. 4C). By in situ hybridization with ER81 (Fig. $4 A-F$ ) and Brn3b (data not shown) probes, we found that IO neurons in $\mathrm{Cdk} 5-/-$ mice were diffusely distributed without forming a typical crescent shape in the medulla at E14.5 (Fig. $4 B$ ). This diffuse pattern of IO neurons observed at E14.5 in the mutant mice persisted through E18.5, whereas typical foliated subdomains were identified in the wild-type mice (Fig. 4C,D). The contralateral IO neurons were labeled by placing DiI in the cerebellum in the wild-type mice (Fig. $4 G$ ). In the Cdk5-/mice, DiI-positive neurons were diffused without segregating into a typical foliated shape at the contralateral side, as revealed by in 


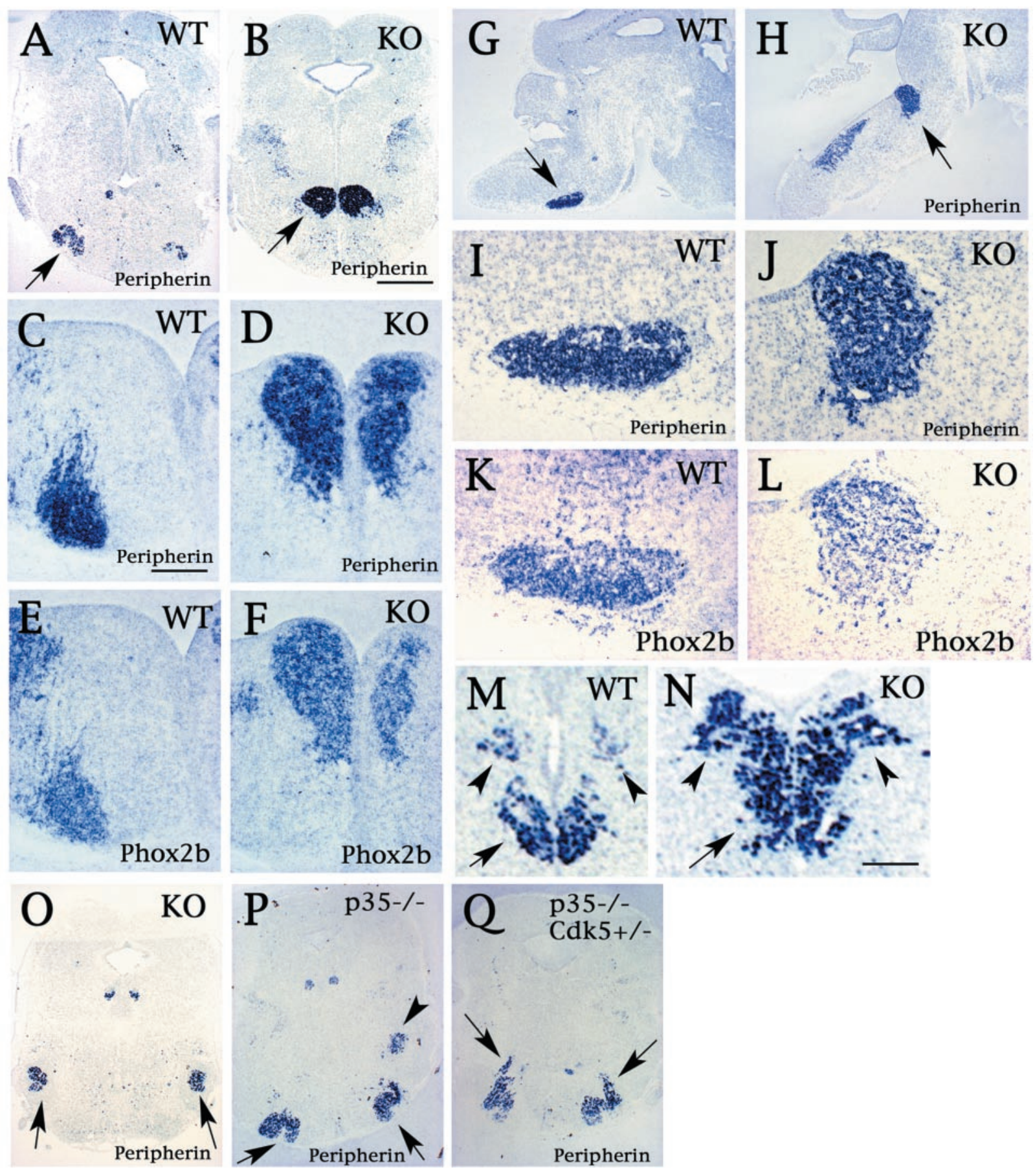

Figure 3. In situ hybridization studies for the Cdk5 mutant hindbrain. Sections were probed with either peripherin $(A-D, G-J)$ or Phox $2 \mathrm{~b}(E, F, K, L)$; these sections were from either Cdk5+/+ $(A, C, E, G, I, K)$ or Cdk5-/- $(B, D, F, H, J, L)$ mouse embryos of age E18.5 $(A, B)$, E14.5 $(C-F)$, and E16.5 $(G-L)$. The sections shown are either coronal $(A-F)$ or sagittal $(G-L)$ sections. The ectopic neuronal mass was identified as VIIth motor nuclei because it stained positive for Phox $2 \mathrm{~b}$ as well as peripherin (arrows in $B$ and $H$ ). $I$ and $J$ are higher magnifications of $G$ and $H$, as indicated with arrows, respectively. The arrow in $A$ indicates the VIIth motor nucleus in $\mathrm{Cdk} 5+/+$ mice. $E, F$, and $K, L$ are serial sections of $C, D$ and $I$, $J$, respectively, hybridized with Phox $2 \mathrm{~b}$ probe. In Cdk5-/- mice $(N, O)$ at E18.5, the motor nuclei of the Vth (arrows in $O$ ), the Xth (arrowheads in $M$ and $N$ ), and the XIIth (arrow in $M$ and $N$ ) nuclei are comparable with $\mathrm{Cdk} 5+/+$ mice $(M)$, as shown by the expression pattern of peripherin. However, segregation of the Xth (arrowheads) and XIIth (arrow) nuclei was less clear in Cdk5-/- mice $(N)$. Although the VIIth nucleus (arrows) appeared normal in p35-/- mice $(P)$, an elongated shape of the VIIth nucleus (arrows) was observed in p35-/-Cdk5+/- mice $(Q)$ at E18.5, as visualized by peripherin expression. The arrowhead in $P$ indicates motor nuclei of the Vth nerve in p35-/- mice. Scale bars: $B, 400 \mu \mathrm{m} ; C, 80 \mu \mathrm{m} ; N, 100 \mu \mathrm{m}$. $W T$, Wild type; KO, knock-out.

situ hybridization (Fig. 4G,H). Thus, the lack of typical structure of the IO complex in $\mathrm{Cdk} 5-/-$ mice is apparently a result of the positioning disturbance of IO neurons through intramural streams from the lower rhombic lip. Interestingly, dislocated IO neurons were found at the parenchyma of the medulla. A comparison of both types of labeling revealed that more neurons stained positive for the IO marker than the DiI-labeled ones, indicating that only a subpopulation of IO neurons have correct 

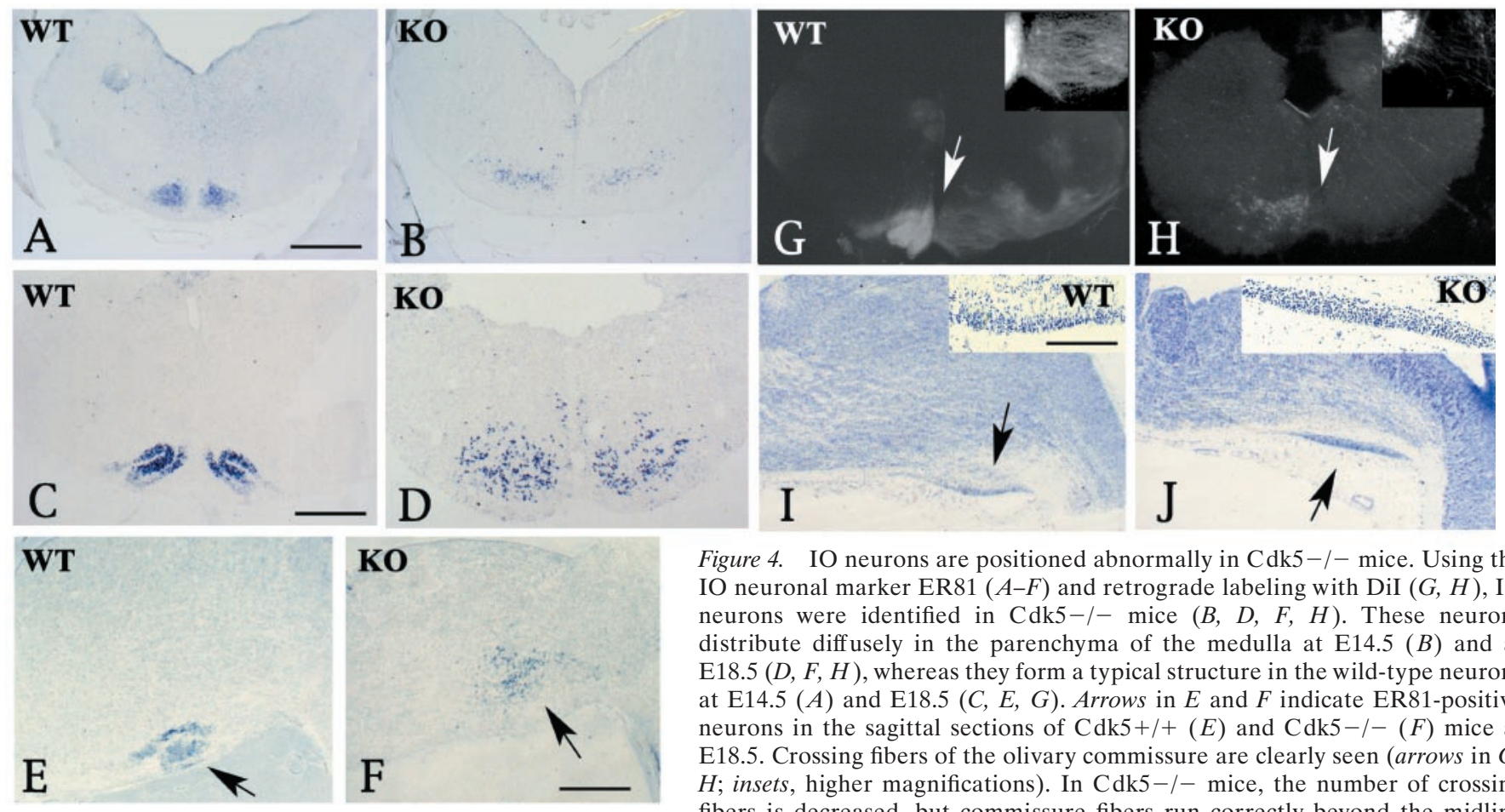

Figure 4. IO neurons are positioned abnormally in $\mathrm{Cdk} 5-/-$ mice. Using the IO neuronal marker ER81 $(A-F)$ and retrograde labeling with DiI $(G, H)$, IO neurons were identified in $\mathrm{Cdk} 5-/-$ mice $(B, D, F, H)$. These neurons distribute diffusely in the parenchyma of the medulla at E14.5 $(B)$ and at E18.5 $(D, F, H)$, whereas they form a typical structure in the wild-type neurons at E14.5 $(A)$ and E18.5 $(C, E, G)$. Arrows in $E$ and $F$ indicate ER81-positive neurons in the sagittal sections of Cdk5+/+ $(E)$ and Cdk5-/- $(F)$ mice at E18.5. Crossing fibers of the olivary commissure are clearly seen (arrows in $G$, $H$; insets, higher magnifications). In $\mathrm{Cdk} 5-/-$ mice, the number of crossing fibers is decreased, but commissure fibers run correctly beyond the midline $(H)$. The posterior extramural stream in Cdk5-/- mice $(J)$ is comparable with that in Cdk5+/+ mice $(I)$ at E14.5, as shown in the Nissl-stained sagittal sections (arrows in $I$ and $J$; insets, higher magnifications). Scale bars: $A, 400 \mu \mathrm{m} ; C, F, 800 \mu \mathrm{m}$; inset in $I, 160 \mu \mathrm{m}$. $W T$, Wild-type; KO, knock-out.

axonal projection to the cerebellum. The extramural migratory stream, which forms the lateral reticular nucleus and external cuneate nucleus, was found to be comparable in appearance in Cdk5-/- and Cdk5+/+ mice at E14.5 (Fig. 4I,J; also see higher magnifications in the insets of $I$ and $J$ ).

\section{Synergistic contribution of Reelin signaling with Cdk5/p35 in the migration of FBM and IO neurons}

Because the specific defects in the migration of FBM and IO neurons seen in $\mathrm{Cdk} 5-/-$ mice have also been reported in reeler mice (Goffinet, 1983, 1984), we have analyzed reelin and Dab1 expression in Cdk5 mutant mice. We first analyzed the expression pattern of Reelin and Dab1 in the Cdk5+/+ and Cdk5-/- mice by in situ hybridization at E14.5 and by immunohistochemistry at E18.5. Dab1 expression was clearly seen in the FBM neurons by in situ hybridization (Fig. 5B,E), whereas Reelin expression was observed in the surrounding areas of FBM neurons in the wildtype mice (Fig. 5A,D). Expression of Dab1 transcripts and protein was clearly seen in the migration-defective FBM neurons of the $\mathrm{Cdk} 5-/-$ mice (Fig. $5 H, K, O$ ).

To study the combined effects of the inactivation of p35 and Dab1, we also studied the migration patterns of FBM and IO neurons in Dab1 mutant yotari mice (Yoneshima et al., 1997) and

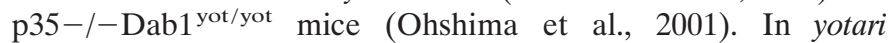
(Dab1 $\left.{ }^{\text {yot/yot }}\right)$ mice, the elongated shapes of the VIIth nuclei were clearly observed at E18.5 (Fig. 6A,C,G). Interestingly, additional defects in the migration patterns of FBM neurons were observed in p35-/-Dab1 ${ }^{\text {yot/yot }}$ mice at E18.5 (Fig. 6B,D,H) as well as at postnatal day 10 (data not shown). Because an abnormal shape of subdivisions of the IO complex has been reported previously in reeler mice (Goffinet, 1983), we subsequently analyzed the IO complex in these mutant mice (Fig. 6I-K). Although we found a similar abnormality in yotari mice (data not shown), interestingly, in p35-/-Dab1 ${ }^{\text {yot/yot }}$ mice, the dorsal accessory olive was found to be shifted laterally compared with those seen in Dab1 ${ }^{\text {yot/yot }}$ or p35-/- mice (Fig. 6M, arrows). These data indicate the synergistic contributions of $\mathrm{Cdk} 5 / \mathrm{p} 35$ and Reelin signaling in the positioning of FBM and IO neurons as well as cortical neurons (Ohshima et al., 2001).

Radial fiber morphology as determined by immunostaining for nestin was not found to be altered in the Cdk5-/- hindbrain (data not shown). Therefore, it is unlikely that defective migration of FBM and IO neurons is caused by a defect in the radial fibers. We also confirmed that these migration defects observed in Cdk5-/- mice occur primarily because of neuronal Cdk5 deficiency in a double-transgenic mouse model ( $\mathrm{Cdk} 5 \mathrm{TgKO})$ in which expression of neuron-specific Cdk5-transgene "rescued" the Cdk5-null phenotype (Tanaka et al., 2001). We examined the location of FBM and IO neurons in Cdk5TgKO mice and wildtype mice. The locations of both FBM and IO neurons were found to be normal in the adult $\mathrm{Cdk} 5 \mathrm{TgKO}$ brain (Fig. 7). Although $\mathrm{Cdk} 5$ is expressed in both neurons and glial cells, a complete rescue of the migration defects of FBM and IO neurons in $\mathrm{Cdk} 5 \mathrm{TgKO}$ also indicates that neuronal migration defects in the hindbrain of $\mathrm{Cdk} 5-/-$ mice are cell autonomous, as shown previously in $\mathrm{Cdk} 5+/+\times \mathrm{Cdk} 5-/-$ chimeric mice (Ohshima et al., 1999).

\section{DISCUSSION}

Our previous studies revealed that abnormal neuronal migration in $\mathrm{Cdk} 5-/-$ mice was associated with defective layer structures in the cerebrum and cerebellum of these mice (Ohshima et al., 1996; Gilmore et al., 1998). In the present study, we have performed an additional detailed analysis of neuronal positioning in the hindbrain of $\mathrm{Cdk} 5-/-$ mice and identified novel migration defects in FBM and IO neurons. Despite these defects in specific neurons, the neurons in other nuclei migrate normally in the 

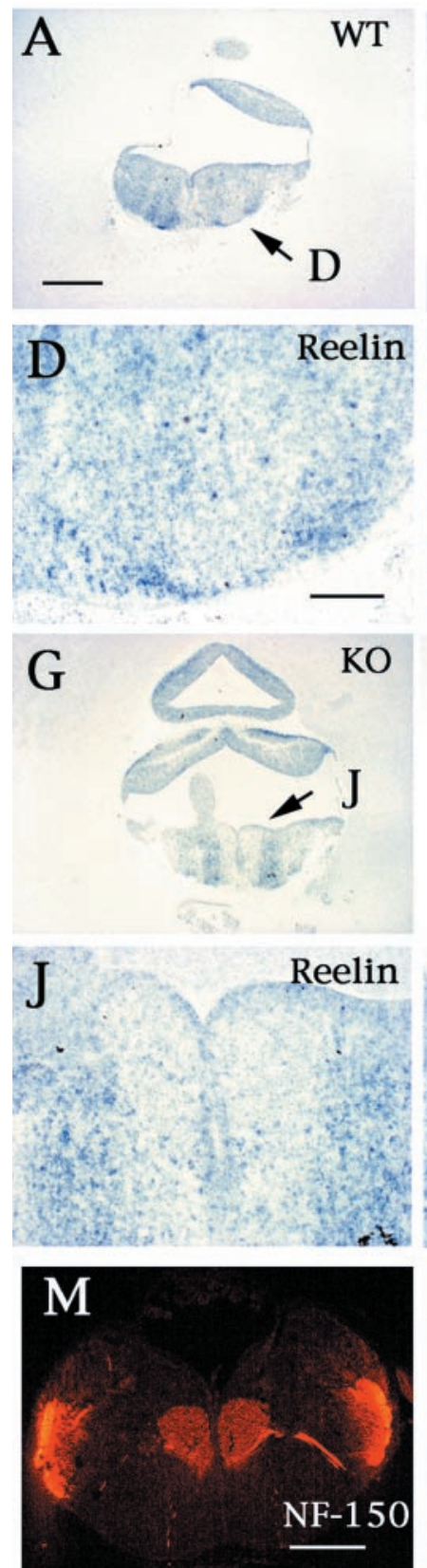
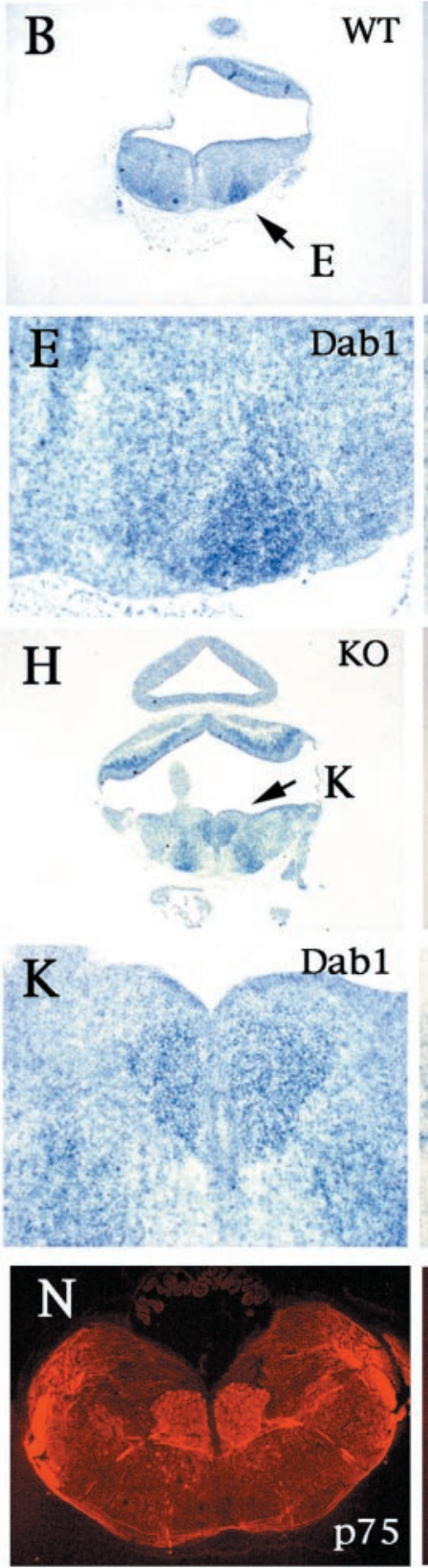
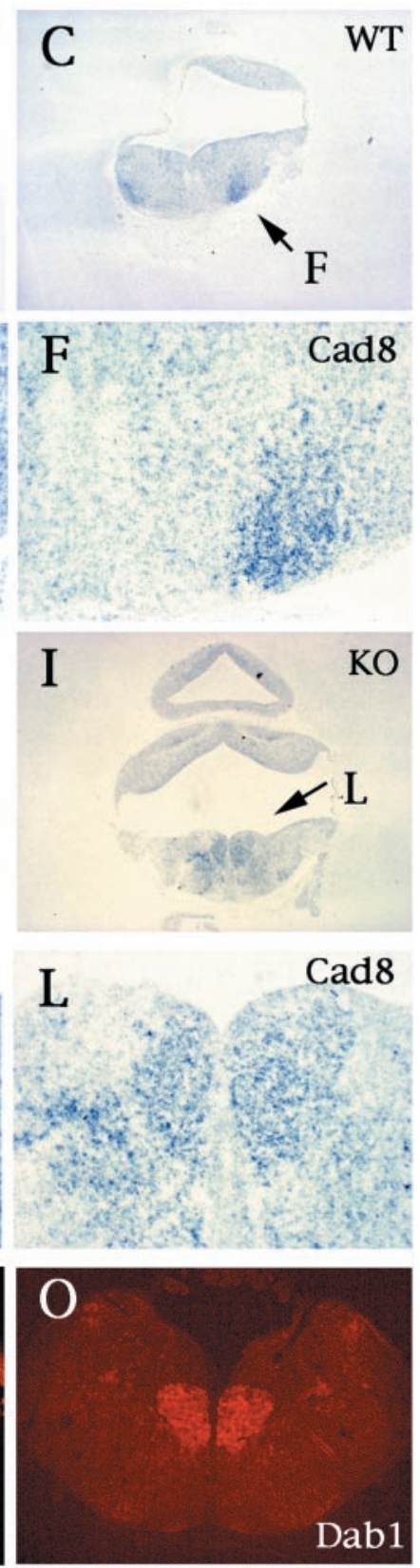

Figure 5. Reelin signaling in the FBM neuronal migration. $A-L$, In situ hybridization study in $\mathrm{Cdk} 5+/+(A-F)$ and Cdk5-/- $(G-L)$ mice at E14.5. $D-F$ and $J-L$ are higher magnifications of $A-C$ and $G-I$ at indicated areas (arrows) in each panel, respectively. The FBM neurons express Dab1 mRNA $(B, E, H$, $K)$, and Reelin mRNA is expressed in the surrounding area at the migratory termination of FBM neurons in the wildtype mice $(A, D)$. Cadherin-8 (Cad 8$)$ expression confirms the identification as FBM neurons in the wild-type $(C, F)$ and $\mathrm{Cdk} 5-/-$ mice $(I, L)$. Migrationarrested FBM neurons also express Dab1 $(O)$ as well as peripherin $(M)$ and neurofilament $(N)$, as shown by the immunostaining of the coronal serial sections of E18.5 Cdk5-/- brain with antiDab1, anti-peripherin, and anti-NF-150 antibodies, respectively. Scale bars: $A$, $300 \mu \mathrm{m} ; D, 80 \mu \mathrm{m} ; M, 400 \mu \mathrm{m}$. WT, Wild type; $K O$, knock-out. hindbrain, indicating that the migration in a selected neuronal population is $\mathrm{Cdk} 5$-dependent. Interestingly, defective neuronal migration in $\mathrm{Cdk} 5-/-$ hindbrain overlaps with the abnormal neuronal migration seen in the hindbrain of the mice with defective Reelin signaling. Most importantly, our study demonstrates a synergistic role of $\mathrm{Cdk} 5 / \mathrm{p} 35$ and Reelin signaling in the migration of a specific neuronal population of the hindbrain.

Many cell populations migrate over long distances and follow complex trajectories from their site of origin to their final destination during the formation of the vertebrate CNS. There are two general modes of neuronal migration in the CNS: nuclear translocation and locomotion (Book and Morest, 1990; Nadarajah et al., 2001). In nuclear (or somal) translocation, the neuron first extends a leading process in the direction of migration, then moves the nucleus (or soma) through this process to its destination. This type of migration has been described in pontine neurons (Yee et al., 1999), in the cerebellum (Hager et al., 1995), and in many other brain areas (Morest, 1970; Gray and Sanes, 1991; Snow and Robson, 1995). Conversely, in the locomotion type of neuronal migration, movement of the entire neuron is involved, including its leading and tailing processes. The radial movement of neurons along the radial fiber is a well defined example of locomotion migration in the cerebral cortex (Rakic, 1972; O'Rourke et al., 1992). The locomotion type of migration of late-born neurons in the cerebral cortex is believed to be Cdk5dependent because of the defective migration observed in Cdk5-/- and p35-/- mice (Gilmore et al., 1998; Kwon and Tsai, 1998).

Among the derivatives from the rhombic lip, migrating granule precursors and pontine neurons exhibit characteristic unipolar morphologies, and a single leading process appears to guide their migration (Ono and Kawamura, 1990; Wingate and Hatten, 1999; Yee et al., 1999), indicating that this type of migration is of a nuclear translocation mode. In the $\mathrm{Cdk} 5-/-$ mice, the external 

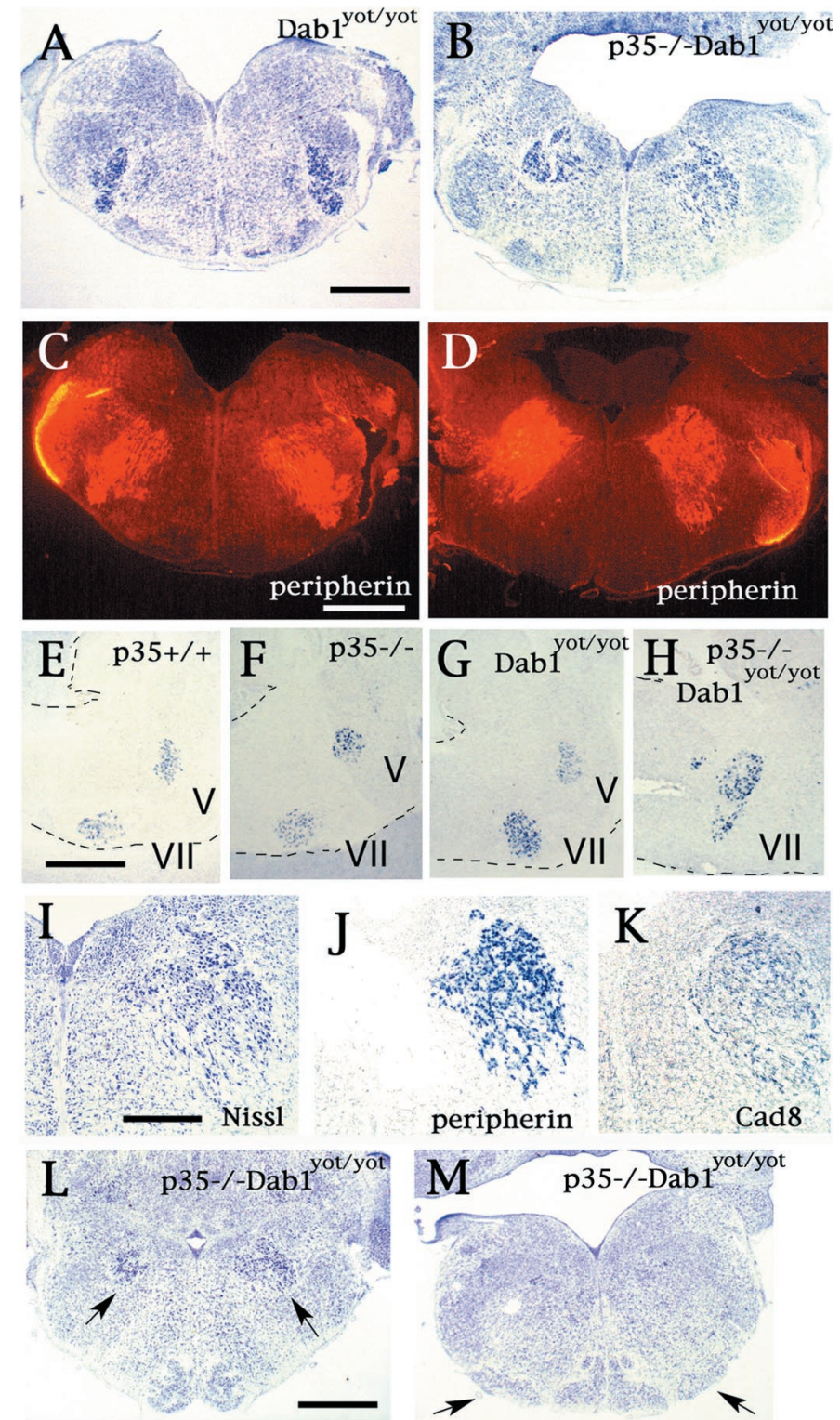

Figure 6. Abnormal FBM neuronal migration in Dab1 ${ }^{\text {yot/yot }}$ and p35-/ -Dab1 $1^{\text {yot/yot }}$ mice. Disturbance of radial migration of FBM neurons in yotari, Dab1 $1^{\text {yot/yot }}$, mice is shown in Nissl-stained $(A)$ and peripherinstained $(C)$ coronal serial sections at E18.5. Deterioration of FBM neuronal migration is advanced in p35-/-Dab1 $1^{\text {yot/yot }}$ mice as seen in Nisslstained $(B)$ and peripherin-stained $(D)$ coronal sections at E18.5. These abnormalities are confirmed by in situ hybridization with a peripherin probe in the sagittal sections from $\mathrm{p} 35+/+(E), \mathrm{p} 35-/-(F)$, Dab1 yot/yot $(G)$, and $\mathrm{p} 35-/-\mathrm{Dab} 1^{\text {yot/yot }}(H)$ mice at P0. Dashed lines indicate the margin of sections. $I-K$, Serial sections in coronal sections are either Nissl-stained $(I)$ or analyzed by in situ hybridization with peripherin probe $(J)$ and cadherin-8 $(\mathrm{Cad} 8)$ probe $(K)$. Abnormally located FBM neurons in $\mathrm{p} 35-/-\mathrm{Dab} 1^{\text {yot/yot }}$ mice are identified by their cadherin- 8 mRNA expression $(K) . L, M$, Migration abnormality of the IO neurons is also detected in rostral $(L)$ and caudal IO $(M)$ sections of p35-/ -Dab1 ${ }^{\text {yot/yot }}$ mice with Nissl stain at P0. Arrows in $L$ indicate ectopically located FBM neurons; arrows in $M$ indicate the dorsal accessory olive, which is located laterally in p35-/-Dab1 ${ }^{\text {yot/yot }}$ mice. Scale bars: $A, 300$ $\mu \mathrm{m} ; E, 240 \mu \mathrm{m} ; I, 60 \mu \mathrm{m}$. $V$, Vth nucleus; VII, Vth nucleus.

granule cell layer of the cerebellum (Ohshima et al., 1999) and the pontine nucleus form normally (Fig. $1 L$ ), indicating that this type of migration of granule precursors and pontine neurons is Cdk5independent. IO neurons are also derivatives of the rhombic lip,
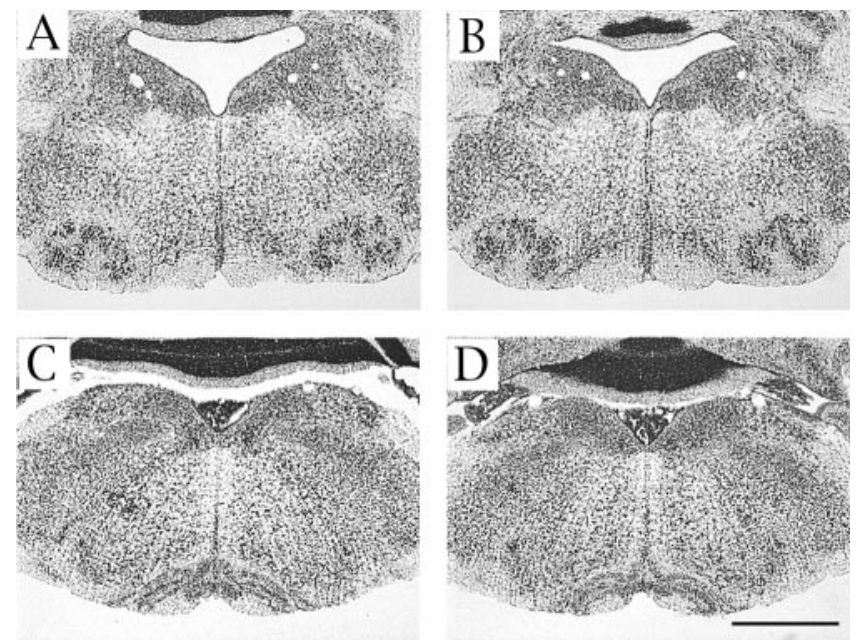

Figure 7. Abnormalities of FBM and IO neurons are rescued by neuronspecific expression of Cdk5 transgene. No abnormality is found in the VIIth motor nucleus and IO complex in Nissl-stained coronal sections from adult $\mathrm{Cdk} 5 \mathrm{TgKO}$ mice $(B, D)$ compared with age-matched wild-type mice $(A, C) . A-D$ are at the same magnification. Scale bar, $1 \mathrm{~mm}$.

but their migration is quite different from that of pontine neurons and other neurons of precerebellar nuclei, which migrate through the anterior extramural stream and posterior extramural stream (Altman and Bayer, 1987, 1997). IO neurons use a distinct migratory pathway called the intramural migration (submarginal) stream (Altman and Bayer, 1997). In Netrin-1-deficient mice, the number of IO neurons is remarkably decreased, and some of them are located ectopically along the intramural migration stream (Bloch-Gallego et al., 1999). Because these ectopic IO neurons lack retrograde DiI labeling from the cerebellum, these neurons are believed to be unable to reach their axons to their targets in the cerebellum (Bloch-Gallego et al., 1999). In Cdk5-/- mice, ectopically located IO neurons are not positioned along their migration stream. They do not make clusters but rather are distributed diffusely in the parenchyma of medulla. Despite their abnormal location, IO neurons in $\mathrm{Cdk} 5-/-$ mice seem to have made correct projections to the cerebellum, as shown in our DiI study, indicating that the climbing fiber is apparently established independently of the ectopic nature of IO neuron position.

The FBM neurons are known to take a complex migration pattern (Auclair et al., 1996; Garel et al., 2000). They are born in the basal plate of rhombomere 4 (r4) between E9 and E14 and migrate caudally through $\mathrm{r} 5$ and then dorsally and radially in $\mathrm{r} 6$. The migration of the cell bodies of FBM neurons is completed by E14. In Cdk5-/- mice, FBM neurons are settled in the location where they are born; therefore, initial tangential migration along the ventral midline is impaired. Despite the defective migration of FBM neurons, the facial nerves formed comparably to those in wild-type littermates and exited correctly at the r4 level. Thus, axonal path-findings of FBM neurons might not be disturbed in Cdk5-/- mice. ChAT staining also indicated that differentiation of ectopic FBM neurons to cholinergic neurons occurs normally in $\mathrm{Cdk} 5-/-$ mice.

Normal migration of FBM neurons in p35-/- mice is apparently a result of redundancy of the Cdk5 activators p35 and p39, particularly because of their overlapping expression in the developing brainstem (Ohshima et al., 2001). However, p35-/Cdk5+/- mice display misplaced FBM neurons because of their 
disturbed radial migration within r6 along the radial fibers in the medulla. This prompts us to believe that the radial migration of FBM neurons is of the locomotive type, a radial fiber-guided migration, and that it may be Cdk5-dependent. Interestingly, Reelin signaling is also involved in this radial migration of FBM neurons, because these neurons express Dab1 (Carroll et al., 2001), and Reelin expression is seen in the area surrounding the facial nucleus at the termination of the migration of these neurons. Furthermore, retarded radial migration of FBM neurons and abnormalities in the architectonic organization of the facial nucleus were described in reeler mice (Goffinet, 1984; Terashima et al., 1993), and our present findings indicating profound disturbances in the last phase of radial migration of FBM neurons in Dab1 mutant yotari mice confirm the important role of Reelin signaling in the migration of FBM neurons.

In the compound mutant mice of p35 and Dab1 or Reelin, an enhanced deterioration was observed in the migration defects of the Purkinje cells in the cerebellum as well as in the pyramidal neurons in the hippocampus, indicating synergistic effects of inactivation of $\mathrm{Cdk} 5 / \mathrm{p} 35$ and Reelin signaling on the migration of these cortical neurons (Ohshima et al., 2001). In the present study, we have observed similar effects in the radial migration of FBM neurons. In p35-/-Dab1 $1^{\text {yot/yot }}$ mice, radial migration of FBM neurons is much more defective than in either the p35-/or Dab1 mutant. Most notably, p35-/- mice have no obvious abnormality in the location of the facial nucleus, whereas the compound mutants do have clear ectopia. This strengthens our belief that Reelin signaling plays a crucial role in the radial migration of FBM neurons. We have not found any abnormality in the radial fiber morphology in $\mathrm{Cdk} 5-/-$ mice; moreover, neuron-specific expression of the $\mathrm{Cdk} 5$ transgene completely rescues the defective migration of FBM and IO neurons in Cdk5-/- mice, indicating that these neuronal migration defects are caused primarily by $\mathrm{Cdk} 5$ kinase deficiency and are cell-autonomous.

Our analysis of neuronal migration in the hindbrain of $\mathrm{Cdk} 5-/-$ mice revealed that the migration of selective populations of neurons is Cdk5-dependent. The impact of Cdk5 deficiency on the neuronal positioning in these neurons is quite distinct. The migration of FBM neurons was completely arrested at the site where they were born, whereas IO neurons migrate close to their final destinations but fail to form the cellular alignment into distinct structures of IO. These observations prompt us to group the defects of neuronal positioning caused by $\mathrm{Cdk} 5$ deficiency into three different categories. The first category contains the FBM neurons and Purkinje cells whose migrations are completely arrested; these neurons are located at the site where they were born. In the second category, the defects disturb the cellular alignment to form a distinct and novel layer or structure in the brain. This includes IO neurons and mitral cells in the olfactory bulb (Ko et al., 2001; T. Ohshima, M. Ogawa, and K. Mikoshiba, unpublished observations). These neurons distribute diffusely near their final destination. The third category contains neurons with a type of defect intermediate between these two patterns. Late-born neurons of the cerebral cortex and pyramidal neurons of the hippocampus can be placed into this group. Several studies indicate that $\mathrm{Cdk} 5 / \mathrm{p} 35$ kinase may regulate actin and/or microtubule dynamics (Paudel et al., 1993; Nikolic et al., 1998; Niethammer et al., 2000; Sasaki et al., 2000) and cell adhesion mediated by N-cadherin (Kwon et al., 2000) during cortical development. Therefore, it is reasonable to hypothesize that an imbalance in $\mathrm{Cdk} 5$-mediated regulation of the actin/microtubule dynamics may cause migration defects similar to those seen in the first category. Conversely, defective regulation of cell adhesion may affect the cell-to-cell interactions important for the cellular alignment needed to form a distinct layer and structure, such as the IO and mitral cell layer of the olfactory bulb. At the same time, it should be pointed out that some of the migration modes of certain hindbrain neurons are $\mathrm{Cdk} 5$-independent. Thus, the precise delineation of Cdk5-dependent migration and its relationship with Reelin signaling will certainly provide valuable insights into the molecular and cellular mechanisms of neuronal migration underlying the precise positioning of the neurons in normal and abnormal brain development.

\section{REFERENCES}

Altman J, Bayer SA (1987) Development of the precerebellar nuclei in the rat: I-IV. J Comp Neurol 257:477-552.

Altman J, Bayer SA (1997) Development of the cerebellar system in relation to its evolution, structure, and functions. Boca Raton, FL: CRC.

Arber S, Ladle DR, Lin JH, Frank E, Jessell TM (2000) EST gene Er81 controls the formation of functional connections between group Ia sensory afferents and motor neurons. Cell 101:485-498.

Auclair F, Valdes N, Marchand R (1996) Rhombomere-specific origin of branchial and visceral motoneurons of the facial nerve in the rat embryo. J Comp Neurol 369:451-461.

Bloch-Gallego E, Ezon F, Tessier-Lavique M, Sotelo C (1999) Floor plate and netrin- 1 are involved in the migration and survival of interior olivary neurons. J Neurosci 19:4407-4420.

Book KJ, Morest DK (1990) Migration of neuroblasts by perikaryal translocation: role of cellular elongation and axonal outgrowth in the acoustic nuclei of the chick embryo medulla. J Comp Neurol 297:55-76.

Carroll P, Gayet O, Feuillet O, Kallenbach S, de Bovis B, Dudley K, Alonso S (2001) Juxtaposition of CNR protocadherins and reelin expression in the developing spinal cord. Mol Cell Neurosci 17:611-623.

Chae T, Kwon YT, Bronson R, Dikkes P, Li E, Tsai L-H (1997) Mice lacking p35, a neuronal specific activator of $\mathrm{Cdk} 5$, display cortical lamination defects, seizures and adult lethality. Neuron 18:29-42.

Chotteau-Lelievre A, Desbiens X, Pelczar H, Defossez PA, de Launoit Y (1997) Differential expression patterns of the PEA3 group transcription factors through murine embryonic development. Oncogene 15:937-952.

D'Arcangelo G, Miao GG, Chen SC, Soares HD, Morgan JI, Curran T (1995) A protein related to extracellular matrix proteins deleted in the mouse mutant reeler. Nature 374:719-723.

Escurat M, Djabali K, Gumpel M, Gros F, Portier MM (1990) Differential expression of two neuronal intermediate-filament proteins, peripherin and the low-molecular-mass neurofilament protein (NF-L), during the development of the rat. J Neurosci 10:764-784.

Garel S, Garcia-Dominguez M, Charnay P (2000) Control of the migratory pathway of facial branchiomotor neurons. Development 127:5297-5307.

Gilmore EC, Ohshima T, Goffinet AM, Kulkarni AB, Herrup K (1998) Cyclin-dependent kinase 5-deficient mice demonstrate novel developmental arrest in cerebral cortex. J Neurosci 18:6370-6377.

Goffinet AM (1983) The embryonic development of the inferior olivary complex in normal and reeler mutant mice. J Comp Neurol 219:10-24.

Goffinet AM (1984) Abnormal development of the facial nerve nucleus in reeler mutant mice. J Anat 138:207-215.

Gray GE, Sanes JR (1991) Migratory paths and phenotypic choices of clonally related cells in the avian optic tectum. Neuron 6:211-225.

Hager G, Dodt H-U, Sieglgansberger W, Liesi P (1995) Novel forms of neuronal migration in the rat cerebellum. J Neurosci Res 40:207-219.

Howell BW, Hawkes R, Soriano P, Cooper JA (1997) Neuronal position in the developing brains is regulated by mouse disabled-1. Nature 389:733-737.

Howell BW, Herrick TM, Cooper JA (1999) Reelin-induced tyrosine phosphorylation of disabled 1 during neuronal positioning. Genes Dev 13:643-648.

Ko J, Humbert S, Bronson RT, Takahashi S, Kulkarni AB, Li E, Tsai L-H (2001) p35 and p39 are essential for cyclin-dependent kinase 5 function during neurodevelopment. J Neurosci 21:6758-6771.

Korematsu K, Redies C (1997) Restricted expression of cadherin-8 in segmental and functional subdivisions of the embryonic mouse brain. Dev Dyn 208:178-189.

Kwon YT, Tsai L-H (1998) A novel disruption of cortical development in p35(-/-) mice distinct from reeler. J Comp Neurol 395:510-522.

Kwon YT, Gupta A, Zhou Y, Nikolic M, Tsai L-H (2000) Regulation of 
$\mathrm{N}$-cadherin-mediated adhesion by the $\mathrm{p} 35 / \mathrm{cdk} 5$ kinase. Curr Biol 10:363-372.

Lew J, Huang QQ, Qi Z, Winkfein RJ, Aebersold R, Hunt T, Wang JH (1994) Neuronal cdc2-like kinase is a complex of cyclin-dependent kinase 5 and a novel brain-specific regulatory subunit. Nature 371:423-426.

Miyata T, Kawaguchi A, Okano H, Ogawa M (2001) Asymmetric inheritance of radial fibers by cortical neurons. Neuron 31:727-741.

Morest DK (1970) A study of neurogenesis in the forebrain of opossum pouch young. Z Anat Entwicklungsgesch 130:265-305.

Nadarajah B, Brunstrom JE, Grutzendler J, Wong ROL, Pearlman AL (2001) Two modes of radial migration in early development of the cerebral cortex. Nat Neurosci 4:143-150.

Niethammer M, Smith DS, Ayala R, Peng J, Ko J, Lee M-S, Morabito M, Tsai L-H (2000) NUDEL is a novel Cdk5 substrate that associates with LIS1 and cytoplasmic dynein. Neuron 28:697-711.

Nikolic M, Chou MM, Lu W, Mayer BJ, Tsai L-H (1998) The p35/Cdk5 kinase is a neuron-specific Rac effector that inhibits Pak1 activity. Nature 395:194-198.

Ogawa M, Miyata T, Nakajima K, Yagyu K, Seike M, Ikenaka KH, Yamamoto H, Mikoshiba K (1995) The reeler gene-associated antigen on Cajal-Retzius neurons is a crucial molecule for laminar organization of cortical neurons. Neuron 14:899-912.

Ohshima T, Ward JM, Huh C-G, Longnecker G, Veeranna, Pant HC, Brady RO, Martin LJ, Kulkarni AB (1996) Targeted disruption of the cdk5 gene results in abnormal corticogenesis, neuronal pathology, and perinatal death. Proc Natl Acad Sci USA 93:11173-11178.

Ohshima T, Gilmore EC, Longenecker G, Jacobowitz DM, Brady RO, Herrup K, Kulkarni AB (1999) Migration defect of cdk5-/- neurons in the developing cerebellum is cell autonomous. J Neurosci 19:6017-6026.

Ohshima T, Ogawa M, Veeranna, Hirasawa M, Longenecker G, Ishiguro K, Pant HC, Brady RO, Kulkarni AB, Mikoshiba K (2001) Synergistic contribution of Cdk5/p35 and Reelin/Dab1 to the positioning of cortical neurons in the developing mouse brain. Proc Natl Acad Sci USA 98:2764-2769.

Ono K, Kawamura K (1990) Mode of neuronal migration of the pontine stream in fetal mice. Anat Embryol 182:11-19.

O'Rourke NA, Dailey ME, Smith SJ, McConnell SK (1992) Diverse migratory pathways in the developing cerebral cortex. Science 258:299-302.

Pattyn A, Hirsch M-R, Goridis C, Brunet J-F (2000) Control of hindbrain motor neuron differentiation by the homeobox gene Phox $2 \mathrm{~b}$. Development 127:1349-1358.

Paudel HK, Lew J, Ali Z, Wang JH (1993) Brain proline-directed kinase phosphorylates tau on sites that are abnormally phosphorylated in tau associated with Alzheimer's paired helical filaments. J Biol Chem 268:23512-23518.
Rakic P (1972) Mode of cell migration to the superficial layers of fetal monkey neocortex. J Comp Neurol 145:61-84.

Rice DS, Sheldon M, D'Arcangelo G, Nakajima K, Goldowitz D, Curran $\mathrm{T}$ (1998) Disabled-1 acts downstream of reelin in a signaling pathway that controls laminar organization in the mammalian brain. Development 125:3719-3729.

Sasaki S, Shionoya A, Ishida M, Gambello MJ, Yingling J, WynshawBoris A, Hirotsune S (2000) A LIS1/NUDEL/cytoplasmic dynein heavy chain complex in the developing and adult nervous system. Neuron 28:681-696.

Sheldon M, Rice DS, D'Arcangelo G, Yoneshima H, Nakajima K, Mikoshiba K, Howell BW, Cooper JA, Goldowitz D, Curran T (1997) Scrambler and yotari disrupt the disabled gene and produce a reelerlike phenotype in mice. Nature 389:730-733.

Snow RL, Robson JA (1995) Migration and differentiation of neurons in the retina and optic tectum of the chick. Exp Neurol 134:13-24.

Tanaka T, Veeranna, Ohshima T, Rajan P, Amin ND, Cho A, Sreenath T, Pant HC, Brady RO, Kulkarni AB (2001) Neuronal cyclindependent kinase 5 activity is critical for survival. J Neurosci 21:550-558.

Tang D, Yeung J, Lee K-Y, Matsushita M, Matsui H, Tomizawa K, Hatase O, Wang JH (1995) An isoform of the neuronal cyclindependent kinase 5 (cdk5) activator. J Biol Chem 270:26897-26903.

Taniguchi M, Yuasa S, Fujisawa H, Naruse I, Saga S, Mishina M, Yagi T (1997) Disruption of semaphorin III/D gene causes severe abnormality in peripheral nerve projection. Neuron 19:519-530.

Terashima T, Kishimoto Y, Ochiishi T (1993) Musculotopic organization of the facial nucleus of the reeler mutant mouse. Brain Res 617:1-9.

Tsai L-H, Takahashi T, Caviness Jr VS, Harlow E (1993) Activity and expression pattern of cyclin-dependent kinase 5 in the embryonic mouse central nervous system. Development 119:1029-1040.

Tsai L-H, Delalle I, Caviness Jr VS, Chae T, Harlow E (1994) p35 is a neuronal-specific regulatory subunit of Cdk5. Nature 371:419-423.

Wingate RJT, Hatten ME (1999) The role of the rhombic lip in avian cerebellum development. Development 126:4395-4404.

Wyatt S, Ensor L, Begbie J, Reichardt LF, Latchman DS (1998) NT-3 regulates expression on Brn-3a but not Brn-3b in developing mouse trigeminal sensory neurons. Brain Res Mol Brain Res 55:254-264.

Yee TT, Simon HH, Tessier-Lavigne M, O'Leary DM (1999) Extension of long leading processes and neuronal migration in the mammalian brain directed by chemoattractant netrin-1. Neuron 24:607-622.

Yoneshima H, Nagata E, Matsumoto M, Yamada M, Nakajima K, Miyata T, Ogawa M, Mikoshiba K (1997) A novel neurological mutant mouse, yotari, which exhibits reeler-like phenotype but expresses CR-50 antigen/Reelin. Neurosci Res 29, 217-223. 